\title{
Characteristics, immobilization, and application of Candida rugosa lipase: a review
}

\author{
*Subroto, E., Indiarto, R., Pangawikan, A.D., Huda, S. and Yarlina, V.P. \\ Department of Food Industrial Technology, Faculty of Agro-Industrial Technology, Universitas \\ Padjadjaran, Jl.Raya Bandung-Sumedang Km. 21, Jatinangor, Sumedang 40600, Indonesia
}

\author{
Article history: \\ Received: 10 February 2020 \\ Received in revised form: 10 \\ March 2020 \\ Accepted: 14 March 2020 \\ Available Online: 5 April \\ 2020
}

\section{Keywords:}

Candida rugosa lipase,

Molecular structure,

Catalytic mechanism,

Immobilization,

Lipid modification

\section{DOI:}

https://doi.org/10.26656/fr.2017.4(5).060

\begin{abstract}
Candida rugosa lipase (CRL) is one of the lipases widely used in various food industries and studies, especially in linkage with the modification of lipids. This review discusses CRL, including CRL features (molecular biology, the structure of the enzyme protein, the flap/ lid), catalytic mechanisms and substrates specificity, CRL immobilization technologies, and various applications in lipid modifications. CRL has five isoenzymes, namely LIP1 - LIP5, then develops again into LIP1 - LIP8. However, LIP1 is the most commonly found isoenzymes. CRL has a structure similar to that of Geotricum candidum lipase, has a flap/ lid, which is an active side cover in the form of $\alpha$-helix, which is relatively shorter than other lipases. The active site of the CRL consists of triads ser-209, His-449, and Glu-341, while the catalytic mechanism of the CRL is the same as the other lipases by the nucleophilic attack. CRL catalyzes triacylglycerol at all positions randomly and has hydrolysis and synthesis activities that are strongly affected by the presence of water in the reaction system. CRL can be used for various lipid modifications through hydrolysis, esterification, interesterification/transesterification, and alcoholysis/ glycerolysis reactions.
\end{abstract}

\section{Introduction}

Candida rugosa lipase (CRL) has been widely studied, which originates from the secretion of microorganisms and is continuously enhanced with various modification and immobilization techniques to increase its utility. CRL is an active protein with a single polypeptide chain consisting of 543 amino acid residues, a molecular weight of about $60 \mathrm{kDa}$. It has a catalytic site composed of three typical amino acid residues (Triads) consisting of Ser209, Glu341, and His449 and it also has a lid on the active site (Lotti and Alberghina, 2007; Vanleeuw et al., 2019). CRL is a biocatalyst that is non-specific to the position of fatty acids or to substrates that contain fatty acids at random in all positions (Tarnowska et al., 2013). Various in-depth knowledge about the structure and kinetics of CRL has increased efficiency for the process of hydrolysis and synthesis, adjustments to specificity, and enzyme immobilization techniques so that the revolution develops rapidly in various fields of bio-industry using CRL (Domínguez De María et al., 2006; Rajendran et al., 2009).

CRLs are more often used in an immobilized form where CRLs are trapped or bound by the support matrix so they can be used repeatedly, and their activity and stability increase (Benjamin and Pandey, 1998; Vanleeuw et al., 2019). The latest CRL immobilization has also evolved, namely, through the formation of nanoparticles. Eco-friendly policy demands encourage the use of environmentally friendly catalysts such as CRL. CRL becomes an environmentally friendly catalyst alternative, especially for the fat and oil industries, biopharmaceuticals, biopesticides, and various other industries. Lipases, including CRL, have been widely used in organic synthesis for the formation of specific chemical compounds and polymeric materials (Cauglia and Canepa, 2008). In the processed fat/oil industry, CRL has been widely used in various hydrolysis reactions that are non-specific or stereospecific and has also been widely used for esterification, alcoholysis, transesterification, acidolysis, and other interesterification reactions. (Vanleeuw et al., 2019). The review is aimed to describe the characteristics of CRL (including catalytic mechanisms and specificity), technology for CRL immobilization, especially discussing the latest CRL immobilization method, namely through the formation of nanoparticles. This review also specifically addresses the application of CRL in lipid modifications and technologies. 


\section{Characteristics of CRL}

CRL has five isoenzymes, each of which has been given a genetic code, namely LIP1 - LIP5, and then develops again into LIP1 - LIP8 (Lotti et al., 1994; Vanleeuw et al., 2019). LIP1 is the most commonly found isoenzymes but each group of isoenzymes (LIP) sequences is interrelated with one another. Products produced by LIP1 are generally the same as lipases produced by $C$. rugosa in general. Overall, lipase proteins in this group have a high homologous sequence ( $84 \%$ of similarity). The differences from these isoenzymes are probably their biochemical properties due to differences in the content of sugar groups, isoelectric $\mathrm{pH}$, and hydrophobicity (Benjamin and Pandey, 1998; Lotti and Alberghina, 2007; Vanleeuw et al., 2019).

In LIP1 there is a hydrophobic bond between Phe344 and Phe87, and a bond between Phe344 and Tyr69. In addition, there was an interaction between Ser84 and Ser450, while alanine was found in position 450, this was not found in LIP3. Therefore, the lid on LIP1 is more stable and flexible when in an open state. LIP1 has excellent lipolytic activity in short and medium-chain fatty acids (C4-C10). LIP2 has a high variation of amino acids in the lid (positions 68-76 and 86-87), which are important zones for substrate recognition. LIP2 has a lid that is more hydrophobic than LIP1 and LIP3. LIP2 has a good affinity for short chains of water-soluble esters. LIP2 has good catalytic activity for medium and longchain fatty acids; LIP2 is also suitable as cholesterol esterase. LIP3 has a homologous lid structure with LIP2 and has biocatalytic activity suitable as cholesterol esterase. LIP3 also has the most suitable activity as pnitrophenyl esters. The lid on LIP4 is the most hydrophobic compared to other isoenzymes, so LIP4 does not present interfacial activation. LIP4 has better heat stability, and its activity is suitable as p-nitrophenyl esters but is more specific for esters of $\mathrm{C} 16$ and C18. LIP5 has a very good affinity for triacylglycerol substrate, and its biocatalytic activity is almost the same as LIP3 (Lotti et al., 1994; Benjamin and Pandey, 1998; Barriuso et al., 2016; Domínguez De María et al., 2006; Vanleeuw et al., 2019) while LIP6-LIP8 is still being studied until now (Kuo et al., 2015).

\subsection{The structure of $C R L$}

\subsubsection{Secondary structure and three-dimensional structure of $C R L$}

The secondary structure of CRL has similarities with lipases from other sources such as lipases from Candida antartica $A$ and deacetylases from Bacillus substilis (Widmann et al., 2010). The CRL has $\alpha$-helix and $\beta$ sheet structures alternating with the $\beta$-sheet mixture in the center, which is catalytic residues. CRL protein is a polypeptide chain that has two terminals ( $\mathrm{N}$-terminal and C-terminal). At $\mathrm{N}$-terminal, there is an active site in the form of a hydrophobic channel from the amino residue Ser209 to the surface of Tyr361 and Ser365, which can accommodate long-chain fatty acids (Pleiss et al., 1998; Kokkonen et al., 2019). This channel can only be found in lipases from Candida rugosa and Geotrichum candidum with a size of $25 \AA$ and tend to have an Lshape suitable for the space requirements of oleic acid structure (Cygler and Schrag, 1999).

Each lipase has a number of helical forms that are above in most active site pockets that play a significant role in interfacial activity and specificity of the substrate. The lid or active site covering of the CRL is marked by $\alpha$ -helices which are relatively short compared to other $\alpha$ helices. The form of X-ray crystallography to CRL has significant similarity with the lipase of $G$. candidum (GCL) and some esterases and acetylcholine esterases (Grochulski et al., 1993). CRL has a catalytic site composed of a triad of Serin-Histidine-Glutamine amino acid residues and has an identical high degree $(>40 \%)$ to the overall length of the polypeptide chain. However, this similarity does not apply to the loops that make up the flaps that cover the active site of the enzyme (Grochulski et al., 1993; Lotti et al., 1994; Domínguez De María et al., 2006).

In the CRL family group, similarity or compatibility includes triad catalytic residues (Ser 209, His449, Glu341), the presence of amino acid residues that form disulfide bridges (Cis60-Cis97 and Cis268-Cis277), amino acid residues that form salt bridges (Arg37 -Glu95 and Glu172-arg279), groups of amino acid residues that vary position for the group of lipase enzymes, and amino acid residues that form oxyanion holes that interact with the substrate (Gly124 and Ala210) (Malcata et al., 1992; Lotti et al., 1994; Vanleeuw et al., 2019).

\subsubsection{Flap/ Lid of CRL}

The active site of the CRL is closed by an $\alpha$-helical amino acid chain (65-94 residues) that is formed from an amphiphilic amino acid chain which is often referred to as a lid lipase. The composition of amino acid chains in lid lipases varies for some isoenzymes. Lid lipase plays a significant role in the enzymatic catalytic activity and enantiomer selectivity (Domínguez De María et al., 2006). The bonds present in lid lipase are disulfide bridges (Cys60-Cys97) and ionic interactions between Glu96 and Arg37. When the lid lipase opens, rotation of the Glu96 and Arg37 residues occurs. The shape of the lid is more natural to open thermodynamically when lipases are on lipophilic or hydrophobic media (Cygler and Schrag, 1999; Turner et al., 2001). The active site of 
the CRL consists of three amino acid chains Ser209Glu341-His449 which are stabilized in the presence of hydrogen bonds (Vanleeuw et al., 2019). This amino acid chain is slightly different for enzymes in crystal form (Mancheño et al., 2003).

Flap/lid of CRL is a cover of the active site of the enzyme composed of amino acid residues which are mostly composed of amino acid residues that are hydrophilic on the surface (outer side), while the part facing the active site is mainly composed of hydrophobic amino acid residues (Lotti et al., 1994; Domínguez De María et al., 2006). Serine residues from the Triad are nucleophilic, which play an essential role in their catalytic activity. The catalytic site part is enclosed by a lid/ flap which is composed of short helix fragments and is stabilized by the presence of hydrophobic and electrostatic interactions. This CRL activation requires conformational rearrangement for opening the lid/ flap. Nevertheless, the triad residue forming the catalytic site can be entered by the substrate if an air-lipid interface is present in the system (Lotti and Alberghina, 2007; Borrelli and Trono, 2015). The flap/ lid on the CRL is similar to the lipase of Geotricum candidum (GCL) with the disulfide bridge and salt bridge connecting 45 amino acid residues (Grochulski et al., 1994). On the inside of the lid, there is a long tunnel, where the activation process involves rearranging the loop other than the flap (Grochulski et al., 1993; Cygler et al., 1995; Cygler and Schrag, 1999).

\subsection{Catalytic mechanisms of CRL}

The catalytic mechanism of CRL has similarities with the mechanism of catalytic lipase in general; the difference is usually only in the amino acid residues that make up the active site (Lotti and Alberghina, 2007; Vanleeuw et al., 2019). The catalytic site of some lipases is usually composed of Serin, Histidine, and Glutamine. Glutamine amino acid residues can be replaced by aspartic acid residues that are both negatively charged. The catalytic mechanism of CRL begins by the binding of lipids or substrates, then activation of nucleophilic serine residues through hydrogen donors to nearby histidine residues followed by nucleophilic attacks by serine residues on ester or lipid substrates to form tetrahedral intermediate conformations. Histidine then donates protons to release the alcohol component from the substrate to form intermediate covalent bonds (acyl enzymes). The acidic component of the substrate is esterified with a serine residue nearby and then water enters to carry out a nucleophilic attack on the $\mathrm{C}$ carbonyl atom in the covalent intermediates. Then histidine residue donates protons taken from water molecules to oxygen atoms in the active serine residue, later the enzyme ester bond with the broken acyl component and the product in the form of acyl (acid) is released (Jaeger et al., 1999; Akoh et al., 2004).

\subsection{Specificity of $C R L$}

The specificity spectrum of CRL is broad, this is mainly affected by the molecular structure of lipase, the substrate, and other factors that can affect the binding of enzymes to the substrate (Jensen, 1983; Kingsley and Lill, 2015). The specificity of the substrate possessed by CRL is almost the same as most other lipases; this indicates the need for science or techniques to increase the utilization of CRL in order to better the specificity of the substrate. Rúa and Ballesteros (1994) studied the characteristic of two forms of CRL (Lipases A and B) on their hydrolysis rate, and it was found that the two lipases showed differences in their $\mathrm{Km}$ values. The lipase B can still consistently follow Michaelis-Menten's kinetics but it has a higher $\mathrm{Km}$ value for p-nitrophenyl butyrate than other ester compounds. Whereas, the two forms of lipase showed similarities and their activity was slow to $20 \mathrm{mM}$ substrate using triolein as substrate, but Lip-B had better hydrolysis ability at higher substrate concentrations. The specificity and activity of CRLs can be increased by various methods, including modifying cell surfaces in CRL-producing yeasts (McMahon et al., 2018; Hao et al., 2019).

CRL can catalyze long-chain triacylglycerols at neutral $\mathrm{pH}$. Three fatty acid chains were fully hydrolyzed from the glycerol backbone at these conditions (Benjamin and Pandey, 1998). Nevertheless, oleic acid and palmitic acid are released more rapidly or hydrolyzed compared to stearic acid. This shows that CRL is easier to hydrolyze shorter fatty acids than longchain fatty acids. CRL is also capable of attacking secondary ester groups in the glycerol backbone (Sn-2) without the need for isomerase enzymes. Liu et al. (1995) studied the selectivity of the trans-esterification reaction of two or more different fatty acids with acyl esters and fatty alcohols. The results showed that transesterification occurred in laurate when butyl palmitate and butyl stearate were used as acyl donors. This indicates that CRL tends to choose fatty acids which have shorter chains. CRLs prefer fatty acids in a row $\mathrm{C} 4$, C8, C10, and C12. CRL also has low activity against long-chain fatty acids with many double bonds (Benjamin and Pandey, 1998).

CRL also has specificity in solvent media. Methanol is known to be very suitable for esterification using a CRL catalyst (Wu et al., 1996; Benjamin and Pandey, 1998). Liu et al. (2013) reported the effect of five organic solvent types as pretreatments with different $\mathrm{P}$ logs on the CRL esterification activity. It is seen that the 
highest esterification activity of CRL is obtained with isooctane with a value of $29,442.8 \mathrm{U} / \mathrm{g}$ protein, and decreasing in order isooctane $>$ petroleum ether $>\mathrm{n}$ hexane $>$ tert-butanol $>$ tert-amyl alcohol. CRL esterification activities are relatively low and they give more hydrophilic solvents (e.g., tert-amyl alcohol and tert-butanol). This is caused by deformation which occurs an essential interaction between water and protein. Hydrophilic solvents will affect the water content in the environment around lipases on the active side, then affect lipase conformation which causes changes in lipase activity.

The choice of organic solvents must pay attention to two things, namely the solubility of the reactants in the solvent and the choice of solvents that are inert in the reaction (Indiarto et al., 2019). Other factors that may need to be considered are density, viscosity, surface tension, toxicity, and cost (Willis and Marangoni, 2002). Yesiloglu and Kilic (2004) compared several organic solvents for the interesterification of glycerol and oleic acid with CRL and pancreatic porcine. The result showed that isooctane and hexane are suitable solvents for the interesterification process. However, CRL shows low esterification activity in benzene and chloroform. The advantages of using organic solvents in lipid modification with lipase are increasing the solubility of substrates in organic solvents such as isooctane and hexane, shift the thermodynamic equilibrium for synthesis than hydrolysis, reduce side reactions due to excess water, facilitate enzyme recovery because it is easier to filtration, product recovery easier due to low boiling point of organic solvents, improve thermal stability of lipase, eliminate microbial contamination, and immobilized lipase can be used several times.

\section{Immobilization of CRL}

The natural lipase is in liquid form but it has relatively low stability and is difficult to use, especially for the commercialization of the production process (Wang et al., 2017; Gonçalves et al., 2018). Therefore, the use of lipase is preferred in an immobilized form since it has several advantages including enzymes that can be used repeatedly, the process can be operated with a continuous system and more easily controlled, products can be separated easily, waste problems can be minimized, enzyme properties (activity and stability) can be adjusted, and handling for the production process becomes cheaper (Osborn and Akoh, 2002; Idris and Bukhari, 2012; Gonçalves et al., 2018).

Lipase immobilization is based on the compatibility of the enzyme with the polymer matrix or the semipermeable membrane, so it is strong enough to maintain its binding with the enzyme protein, especially when there is diffusion or mass transfer from the substrate to the product (Homaei et al., 2013). In general, agents for CRL immobilization that are quite modern among them are Glass bead, Celite, Chitosan, Nylon fiber, Silk woven fabric, Polymer methacrylate, Woolen cloth, Kieselguhr, octyl-Sepharose beads, Colloidal liquid aphrons, Polyester fiber, SBA-15, Silica gel, and Amberlite IRA96. The CRL immobilization method does not differentiate between LIP1-LIP8 isoenzymes. Several methods and types of matrices for CRL immobilization can be seen in Table 1 .

A variety of different methods have been applied to lipase immobilization. Covalent binding methods have been widely used to bind lipases to polysaccharides, polyacrylamide gels, and carboxyl metal cellulose (Datta

Table 1. Several methods and matrices for CRL immobilization

\begin{tabular}{|c|c|c|}
\hline Immobilization method & Type of matrix & References \\
\hline \multirow{4}{*}{ Adsorption } & \multicolumn{2}{|c|}{ Hydrophobic and hydrophilic-hydrophobic Amberlite IRA-96 (Hilmanto et al., 2016) } \\
\hline & Hydrophilic and hydrophobic Magnetic Silica Aerogel & (Amirkhani et al., 2016) \\
\hline & Celite 545, Sephadex G-25, and chitosan & (Kaja et al., 2018) \\
\hline & Biochar & (Cea et al., 2019) \\
\hline \multirow{4}{*}{ Covalent binding } & Glutaraldehyde-activated aminopropyl glass beads & (Yilmaz et al., 2011) \\
\hline & Poly(ethylene terephthalate) grafted acrylamide fiber & (Yigitoglu and Temoçin, 2010) \\
\hline & Functionalized magnetic Fe3O4 nanoparticles & (Hadadi and Habibi, 2019) \\
\hline & Modified natural wool fiber & (Monier et al., 2010) \\
\hline \multirow{3}{*}{ Entrapment } & Alginate beads & (Tarnowska et al., 2013) \\
\hline & Ca-alginate Beads & (Bhushan et al., 2008) \\
\hline & Hydrolyzed tetramethoxysilane and isobutyltrimethoxysilane & (Noureddini et al., 2003) \\
\hline \multirow{3}{*}{ Nanoparticles } & Magnetic nanoparticles & (Sharma et al., 2019) \\
\hline & Exfoliated graphene oxide & (Patel et al., 2015) \\
\hline & Chitosan-reinforced nanocellulose & (Elias et al., 2019) \\
\hline
\end{tabular}


et al., 2013; Ali et al., 2017). Photo-cross-linkable resins have also been used to adsorb lipases in amphiphilic gels with various types of membranes, such as in cellulose membranes. Lipase immobilization through the adsorption method on a hydrophobically modified matrix is increasingly developing due to the environmental conditions of the matrix which are compatible with the active site of the lipase for easy opening (Chen et al., 2012; Subroto et al., 2020). Enzyme environmental conditions both in the tunnels and channels are very influential in the activity and specificity of enzyme catalytic (Kokkonen et al., 2019).

The immobilization of CRL on the hydrophobic modified IRA 96 Amberlite matrix was carried out by Hilmanto et al. (2016) with the addition of $12.5 \%$ Phenylpropionaldehyde in methanol for 2 hours. Lipases can be immobilized completely in a hydrophobic matrix. The higher the hydrophobic of a matrix, the faster the equilibrium is achieved (Sabuquillo et al., 1998). Amirkhani et al. (2016) have also immobilized CRL by adsorption methods on hydrophilic and hydrophobic modified magnetic silica matrix. The results showed that CRL immobilized on a hydrophobically modified matrix with hexamethyldisilazane had higher catalytic activity than the hydrophilic matrix. Matrix surface modification is not only limited to compounds that give hydrophobic character. The use of hydrophilic compounds has also been conducted but hydrophilic modification can cause lipase to prefer water and encourage hydrolysis reaction rather than esterification (Hilmanto et al., 2016). CRL immobilization has also been developed through a method of binding to a matrix coated with a surfactant to improve lipase performance and stability. CRL works better when it is in an emulsion system where there is a surfactant or emulsifier (Wu et al., 2003).

Currently, the CRL immobilization method is also widely developed through the formation of nanoparticles. Sharma et al. (2019) succeeded in producing CRL nanoparticles through the nanoprecipitation technique by crosslinking to Methyl- $\beta$ cyclodextrin. The result of CRL nanoparticles was able to catalyze biodiesel production with performance reaching $100 \%$, which CRL nanoparticles can be used up to 5 times and stable in storage at $4^{\circ} \mathrm{C}$ for 40 days. Patel et al. (2015) have successfully immobilized CRL in exfoliated graphene oxide in the form of nanoparticles for the synthesis of ethyl caprylate. The result showed that immobilized CRL was able to produce ethyl caprylate yield reaching $85 \%$, it is higher than free CRL which only reached $62 \%$ yield. Immobilized CRL can be used up to 30 times, which is able to maintain its activity $50 \%$ of the initial activity. Elias et al. (2019) also succeeded in developing a CRL that was immobilized and activated using chitosan-reinforced Nanocellulose for the synthesis of butyl butyrate through the reaction of esterification of butyric acid with butanol. The result showed that CRL-chitosan-reinforced Nanocellulose had better catalytic efficiency than free CRL.

\section{Use/application of CRL}

CRL has great potential to be used or applied to various industries, including for the production of fatty acids and glycerol through fat/oil hydrolysis, modification of composition and physical properties of the triacylglycerol mixtures through interesterification/ transesterification, alcoholysis/glycerolysis, and synthesis of other chemicals (Benjamin and Pandey, 1998; Li et al., 2018; Vanleeuw et al., 2019). Some CRL applications for various enzymatic processing can be seen in Table 2.

\subsection{Hydrolysis and esterification}

In general, the reaction which is catalyzed by lipase is a combination of esterification and hydrolysis reaction (back and forth reaction) (Akoh et al., 2004). The tendency of the hydrolysis reaction to occur more easily than esterification is strongly affected by the concentration of water in the reaction system. When there is excess water, the hydrolysis reaction will dominate, resulting in the accumulation of free fatty acids (FFAs), monoacylglycerols (MAGs), and diacylglycerols (DAGs). CRL has the ability and activity that is good for the hydrolysis process. CRL has been widely used for the hydrolysis of various types of fats and oils with satisfactory results (Yigitoglu and Temoçin, 2010; Kahveci and $\mathrm{Xu}, 2011)$. In addition, CRL is also known to be able to hydrolyze a wide variety of synthetic esters and some of the hydrolysis reaction is enantioselective or selective to stereoisomer configurations. Therefore CRL is suitable to be used to synthesize pure enantiomers in the sentiment of organic compounds. The resulting product is needed mainly in pharmaceuticals, where purity enantiomerically will optimize the resulting product and minimize side products. The use of CRL which has been widely applied among others is in the production of pure enantiomeric ibuprofen (Yilmaz et al., 2011; Vanleeuw et al., 2019).

Some researchers also utilize CRL for the esterification process to produce various ester products. CRL has been used by Elias et al. (2019) for the esterification of butanol with butyric acid. The result showed that immobilized CRL was able to esterify and produce butyl butyrate effectively. Hilmanto et al. (2016) utilized immobilized CRLs on the hydrophilichydrophobic modified Amberlite IRA-96 matrix for the synthesis of fructose oleic ester through the esterification 
Table 2. CRL applications for various enzymatic processing.

\begin{tabular}{cll}
\hline Type of process & \multicolumn{1}{c}{ Products } & \multicolumn{1}{c}{ References } \\
\hline \multirow{2}{*}{ Hydrolysis } & Salmon oil enriched in omega 3 & (Kahveci and Xu, 2011) \\
& Ricinoleic acid from castor oil & (Zhao et al., 2018) \\
& Linoleic Acid from safflower oil & (Aziz et al., 2015) \\
\hline \multirow{2}{*}{ Esterification } & Butyl butyrate & (Elias et al., 2019) \\
& Fructose Oleic Ester & (Hilmanto et al., 2016) \\
& Ethyl oleate & (Cea et al., 2019) \\
& Geranyl acetate & (Rosa et al., 2017) \\
\hline \multirow{2}{*}{ Interesterification } & fatty acid alkyl esters from palm oil & (Kautsari et al., 2016) \\
& Structured lipid from goose fat and rapeseed oil & (Tarnowska et al., 2013) \\
& Human milk fat substitute & (Srivastava et al., 2006) \\
\hline Alcoholysis & Biodiesel & (Chang et al., 2014; Sharma et al., 2019) \\
\hline \multirow{2}{*}{ Glycerolysis } & Mono- and diacylglycerols from olive oil & (Singh and Mausumi, 2016) \\
& Monoacylglycerols from palm olein & (Kaewthong et al., 2005) \\
& Monoacylglycerols from olive oil & (Fonseca-Dias and da Fonseca, 1995) \\
\hline
\end{tabular}

reaction between fructose and oleic acid. At optimum conditions, the yield reached $85.29 \%$ in the reaction for 18 hours. In another study, Cea et al. (2019) reported that CRL immobilized in biochar could be effectively used for esterification between ethanol and oleic acid, whereas Rosa et al. (2017) reported that CRL could be used to esterify geraniol with vinyl acetate effectively. The yield of acetate geranyl esters about $79 \%$.

\subsection{Interesterification/transesterification}

Interesterification/transesterification reactions have developed rapidly in the field of lipase biotechnology, especially for structured lipid synthesis (Kim and Akoh, 2015). In the transesterification reaction, the ester acts as the donor. The transesterification reaction is mostly done for fat/oil modification. Transesterification can be used to change the physical properties of fats or oils or oil-fat mixtures by changing the position of the fatty acid distribution position on the triacylglycerol backbone. The composition and position of fatty acids determine the plasticity properties of fat products such as butter, especially recombined butter that uses two or more sources of fat (Subroto et al., 2018). Transesterification of butter with nonspecific lipase was reported to increase the plasticity of the butter produced (Willis and Marangoni, 2002). In the interesterification reaction, the amount of water content needs to be controlled to keep the enzyme in an active hydrated condition. The presence of excess water will reduce the amount of synthesized esters. The water content must be carefully adjusted to obtain the maximum amount of desired product accumulation (Rezaei et al., 2007).

CRL has been used for interesterification or transesterification processes, although CRL activity is relatively low for interesterification compared to other lipases. Kautsari et al. (2016) synthesized fatty acid alkyl esters through interesterification between palm oil and ethyl acetate and propyl acetate using CRL which was immobilized in $\mathrm{Fe}_{3} \mathrm{O}_{4}$-polydopamine nanoparticles. Fatty acid ethyl ester and fatty acid propyl ester obtained were about $9.93 \%$ and $9.88 \%$, respectively. Tarnowska et al. (2013) interesterified goose fat and rapeseed oil using a CRL that was immobilized by alginate beads. The result showed that the interesterification of fat experienced random changes in the position of sn-2 and sn-1,3. In addition, the results of oxidation stability testing showed that the interesterified fats also had reduced oxidative stability. Lai et al. (1998) compared several types of lipases, including CRL for transesterification of a mixture of palm stearin with sunflower oil. The result showed that the CRL had a relatively low degree of transesterification of $6.2 \%$ at $60^{\circ} \mathrm{C}$ for $8 \mathrm{hrs}$. The comparison of the degree of transesterification from the highest to low successive is lipase from Pseudomonas, $R$. miehei, A. niger, M. javanicus, R. javanicus, C. rugosa, and $R$. niveus. CRL can also be used for the production of human milk fat substitutes. Srivastava et al. (2006) utilized CRL LIP1 as a catalyst for the interesterification of tripalmitin with oleic acid and methyl oleate. The result showed that CRL was quite effective in incorporating oleic acid about $37.7 \%$ using methyl oleate as an acyl donor. The resulting structured lipids are also similar to human milk fat.

\subsection{Alcoholysis and glycerolysis}

The reaction of alcoholysis and glycerolysis refers to the transfer of the acyl group from triglycerides to other alcohols or glycerol. Alcoholysis has been used for the production of biodiesel in the form of methyl esters from the reaction between triacylglycerol and methanol. Sharma et al. (2019) produced biodiesel using 
immobilized CRL shows that CRL is able to convert brown grease (BG) and used cooking oil (UCO) into methyl esters with up to $100 \%$ performance. Whereas Chang et al. (2014) produced fatty acid methyl esters (FAMEs) through methanolysis soybean oil with methanol using recombinant CRL isozymes (LIP1LIP4). The results showed that CRL (LIP1) had the highest catalytic efficiency. The resulting FAMEs conversion reached $61.5 \%$. In addition, byproducts obtained in the form of diacylglycerol (DAG) reached $10 \%$, which indicates that CRL is potentially suitable for the glycerolysis reaction. One type of alcoholysis that is also often used is ethanolysis, where ethanol acts as a solvent as well as a substrate. In ethanolysis, ethyl esters need to be produced first from free fatty acids which are used as substrates and become reaction products (Nitbani et al., 2015).

Alcoholysis reaction can also be applied to obtain MAG and DAG. The use of alcoholysis, which is currently growing rapidly is for the glycerolysis reaction, namely the exchange of acyl groups between triacylglycerol and glycerol to produce monoacylglycerol (MAG) and diacylglycerol (DAG). Monoacylglycerol and diacylglycerol are very important for the food industry, especially as emulsifiers and surface-active agents (Singh and Mausumi, 2016; Subroto, 2020). Monoacylglycerol can be produced by changing or forming ester bonds from the reaction between triacylglycerol and glycerol or between free fatty acids and glycerol. Glycerolysis is usually done using non-specific lipases which can produce more yield (Willis and Marangoni, 2002; Subroto et al., 2019). Kaewthong et al. (2005) experimented glycerolysis of palm olein used several lipases, including CRL but it obtained CRL is less useful for glycerolysis compared to lipases from other sources such as those from Rhizopus delemar, Pseudomonas sp., Rhizopus oryzae, Alcaligenes sp., and Chromobacterium viscosum. Singh and Mausumi (2016) reported that CRL Immobilized Onto Cellulose Acetate-Coated $\mathrm{Fe}_{2} \mathrm{O}_{3}$ Nanoparticles could be used for glycerolysis of olive oil to produce MAG and DAG about $49.7 \%$ and $17.4 \%$, respectively.

\section{Conclusion}

CRL has a unique structure and properties. CRL has been widely used as a catalyst for various enzymatic processes, especially for lipid modification. Catalytic activity is widespread for several substrates and can catalyze fatty acids at all positions $(\mathrm{sn}-1,2,3)$ of the glycerol backbone. Optimization of the CRL reaction parameters can be carried out by molecular restructuring through genetic engineering to produce a CRL that has better activity and stability. The application of CRL can be improved by CRL immobilization to increase its stability and to be used repeatedly. CRL has great potential to be applied to various enzymatic processes, especially for fat/oil modification through hydrolysis, alcoholysis, glycerolysis, and interesterification reactions.

\section{Conflict of interest}

The author declare no conflict of interest.

\section{Acknowledgments}

The authors would like to thank the Rector of Universitas Padjadjaran, and the Ministry of Education and Culture of the Republic of Indonesia for the support provided.

\section{References}

Akoh, C.C., Lee, G.C. and Shaw, J.F. (2004). Protein engineering and applications of Candida rugosa lipase isoforms. Lipids, 39(6), 513-526. https:// doi.org/10.1007/s11745-004-1258-7

Ali, S., Zafar, W., Shafiq, S. and Manzoor, M. (2017). Enzymes Immobilization: An Overview Of Techniques, Support Materials And Its Applications. International Journal of Science Technology Research, 6, 64-72.

Amirkhani, L., Moghaddas, J. and Jafarizadeh-Malmiri, H. (2016). Optimization of Candida rugosa Lipase Immobilization Parameters on Magnetic Silica Aerogel Using Adsorption Method. Iranian Journal of Chemistry and Engineering, 13, 19-31.

Aziz, M., Husson, F. and Kermasha, S. (2015). Optimization of the Hydrolysis of Safflower Oil for the Production of Linoleic Acid, Used as Flavor Precursor. International Journal of Food Science, 2015, 594238. https://doi.org/10.1155/2015/594238

Barriuso, J., Vaquero, M.E., Prieto, A. and Martínez, M.J. (2016). Structural traits and catalytic versatility of the lipases from the Candida rugosa-like family: A review. Biotechnology Advances, 34(5), 874-885. https://doi.org/10.1016/j.biotechadv.2016.05.004

Benjamin, S. and Pandey, A. (1998). Candida rugosa lipases: Molecular biology and versatility in biotechnology. Yeast, 14(12), 1069-1087. https:// doi.org/10.1002/(SICI)1097-0061(19980915) 14:12<1069::AID-YEA303>3.0.CO;2-K

Bhushan, I., Parshad, R., Qazi, G.N. and Gupta, V.K. (2008). Immobilization of Lipase by Entrapment in Ca-alginate Beads. Journal of Bioactive and Compatible Polymers, 23(6), 552-562. https:// doi.org/10.1177/0883911508097866 
Borrelli, G.M. and Trono, D. (2015). Recombinant lipases and phospholipases and their use as biocatalysts for industrial applications. International Journal of Molecular Sciences, 16(9), 20774-20840. https://doi.org/10.3390/ijms160920774

Cauglia, F. and Canepa, P. (2008). The enzymatic synthesis of glucosylmyristate as a reaction model for general considerations on "sugar esters" production. Bioresource Technology, 99(10), 40654072. https://doi.org/10.1016/j.biortech.2007.01.036

Cea, M., González, M.E., Abarzúa, M. and Navia, R. (2019). Enzymatic esterification of oleic acid by Candida rugosa lipase immobilized onto biochar. Journal of Environmental Management, 242, 171177. https://doi.org/10.1016/j.jenvman.2019.04.013

Chang, S., Huang, M., Hsieh, Y., Luo, Y., Wu, T., Tsai, C., Chen, C. and Shaw, J. (2014). Simultaneous production of fatty acid methyl esters and diglycerides by four recombinant Candida rugosa lipase' s isozymes. Food Chemistry, 155, 140-145. https://doi.org/10.1016/j.foodchem.2014.01.035

Chen, B., Yin, C., Cheng, Y., Li, W., Cao, Z.A. and Tan, T. (2012). Using silk woven fabric as support for lipase immobilization: The effect of surface hydrophilicity/hydrophobicity on enzymatic activity and stability. Biomass and Bioenergy, 39, 59-66. https://doi.org/10.1016/j.biombioe.2010.08.033

Cygler, M., Grochulski, P. and Schrag, J.D. (1995). Substrate Binding Site and the Role of the FLAP Loop in Candida rugosa Lipase, A Close Relative of Acetylcholinesterase. In Quinn, D.M., Balasubramanian, A.S., Doctor, B.P. and Taylor, P. (Eds.). Enzymes of the Cholinesterase Family., p.7176. Boston, USA: Springer. https:// doi.org/10.1007/978-1-4899-1051-6_17

Cygler, M. and Schrag, J.D. (1999). Structure and conformational flexibility of Candida rugosa lipase. Biochimica et Biophysica Acta-Molecular and Cell Biology of Lipids, 1441(2-3), 205-214. https:// doi.org/10.1016/S1388-1981(99)00152-3

Datta, S., Christena, L.R. and Rajaram, Y.R.S. (2013). Enzyme immobilization: an overview on techniques and support materials. 3 Biotech, 3, 1-9. https:// doi.org/10.1007/s13205-012-0071-7

Domínguez De María, P., Sánchez-Montero, J.M., Sinisterra, J.V. and Alcántara, A.R. (2006). Understanding Candida rugosa lipases: An overview. Biotechnology Advances, 24(2), 180-196. https://doi.org/10.1016/j.biotechadv.2005.09.003

Elias, N., Wahab, R.A., Chandren, S., Abdul Razak, F.I. and Jamalis, J. (2019). Effect of operative variables and kinetic study of butyl butyrate synthesis by
Candida rugosa lipase activated by chitosanreinforced nanocellulose derived from raw oil palm leaves. Enzyme and Microbial Technology, 130. https://doi.org/10.1016/j.enzmictec.2019.109367

Fonseca-Dias, S. and da Fonseca, M.M.R. (1995). Glycerolysis of olive oil : batch operational stability of Candida rugosa lipase immobilized in hydrophilic polyurethane foams. Bioprocess Engineering, 13, 311-315. https://doi.org/10.1007/BF00369563

Gonçalves, M.C.P., Kieckbusch, T.G., Perna, R.F., Fujimoto, J.T., Morales, S.A.V. and Romanelli, J.P. (2018). Trends on enzyme immobilization researches based on bibliometric analysis. Process Biochemistry, 75 95-110. https://doi.org/10.1016/ j.procbio.2018.09.016

Grochulski, P., Li, Y., Schrag, J.D., Bouthillier, F., Smith, P., Harrison, D., Rubin, B. and Cygler, M. (1993). Insights into interfacial activation from an open structure of Candida rugosa lipase. Journal of Biological Chemistry, 268, 12843-12847. https:// doi.org/10.2210/pdb1 crl/pdb

Grochulski, P., Li, Y., Schrag, J.D. and Cygler, M. (1994). Two conformational states of Candida rugosa lipase. Protein Sciences, 3(1), 82-91. https:// doi.org/10.1002/pro.5560030111

Hadadi, M. and Habibi, A. (2019). Candida rugosa lipase immobilized on functionalized magnetic Fe3O4 nanoparticles as a sustainable catalyst for production of natural epoxides. Chemical Papers, 73, 1917-1929. https://doi.org/10.1007/s11696-01900741-w

Hao, Y., Zheng, X., Zhang, X., Zhang, K., Lin, Y. and Liang, S. (2019). Combined strategies for engineering a novel whole-cell biocatalyst of Candida rugosa lipase with improved characteristics. Biochemical Engineering Journal, 151, $107337 . \quad$ https://doi.org/10.1016/ j.bej.2019.107337

Hilmanto, H., Hidayat, C. and Hastuti, P. (2016). Surface Modification of Macroporous Matrix for Immobilization of Lipase for Fructose Oleic Ester Synthesis. Bulletin of Chemical Reaction Engineering and Catalysis, 11, 339-345. https:// doi.org/10.9767/bcrec.11.3.573.339-345

Homaei, A.A., Sariri, R., Vianello, F. and Stevanato, R. (2013). Enzyme immobilization: An update. Journal of Chemical Biology, 6, 185-205. https:// doi.org/10.1007/s12154-013-0102-9

Idris, A. and Bukhari, A. (2012). Immobilized Candida antarctica lipase B: Hydration, stripping off and application in ring opening polyester synthesis. Biotechnology Advances, 30(3), 550-563. https:// 
doi.org/10.1016/j.biotechadv.2011.10.002

Indiarto, R., Pranoto, Y., Santoso, U. and Supriyanto (2019). In vitro antioxidant activity and profile of polyphenol compounds extracts and their fractions on cacao beans. Pakistan Journal of Biological Sciences, 22(1), 34-44. https://doi.org/10.3923/ pjbs.2019.34.44

Jaeger, K.-E., Dijkstra, B.W. and Reetz, M.T. (1999). Bacterial Biocatalysts: Molecular Biology, ThreeDimensional Structures, and Biotechnological Applications of Lipases. Annual Review of Microbiology, 53, 315-351. https://doi.org/10.1146/ annurev.micro.53.1.315

Jensen, R.G. (1983). Detection and determination of lipase (acylglycerol hydrolase) activity from various sources. Lipids, 18(9), 650-657. https:// doi.org/10.1007/BF02534677

Kaewthong, W., Sirisansaneeyakul, S., Prasertsan, P. and H-Kittikun, A. (2005). Continuous production of monoacylglycerols by glycerolysis of palm olein with immobilized lipase. Process Biochemistry, 40 (5), 1525-1530. https://doi.org/10.1016/ j.procbio.2003.12.002

Kahveci, D. and Xu, X. (2011). Repeated hydrolysis process is effective for enrichment of omega 3 polyunsaturated fatty acids in salmon oil by Candida rugosa lipase. Food Chemistry, 129(4), 1552-1558. https://doi.org/10.1016/j.foodchem.2011.05.142

Kaja, B.S., Lumor, S., Besong, S., Taylor, B. and Ozbay, G. (2018). Investigating Enzyme Activity of Immobilized Candida rugosa Lipase. Journal of Food Qualilty, 2018, 1618085. https:// doi.org/10.1155/2018/1618085

Kautsari, S.N., Handayani, S. and Hudiyono, S. (2016). Interesterification of palm oil by using immobilized Candida rugosa lipase on $\mathrm{Fe}_{3} \mathrm{O}_{4}$ - polydopamine nanoparticles. AIP Conference Proceedings, 1729 (1), 3-7. https://doi.org/10.1063/1.4946962

Kim, B.H. and Akoh, C.C. (2015). Recent Research Trends on the Enzymatic Synthesis of Structured Lipids. Journal of Food Science, 80(8), 1713-1724. https://doi.org/10.1111/1750-3841.12953

Kingsley, L. and Lill, M. (2015). Substrate Tunnels in Enzymes: Structure-Function Relationships and Computational Methodology. Proteins, 83(4), 599611. https://doi.org/10.1002/prot.24772

Kokkonen, P., Bednar, D., Pinto, G., Prokop, Z. and Damborsky, J. (2019). Engineering enzyme access tunnels. Biotechnology Advances, 37(6), 107386. https://doi.org/10.1016/j.biotechadv.2019.04.008

Kuo, T.C., Shaw, J.F. and Lee, G.C. (2015). Improvement in the secretory expression of recombinant Candida rugosa lipase in Pichia pastoris. Process Biochemistry, 50(12), 2137-2143. https://doi.org/10.1016/j.procbio.2015.09.013

Lai, O.M., Ghazali, H.M. and Chong, C.L. (1998). Effect of enzymatic transesterification on the melting points of palm stearin-sunflower oil mixtures. Journal of American Oil Chemical Society, 75(7), 881-886. https://doi.org/10.1007/s11746-998-0241-2

Li, G., Chen, Y., Fang, X., Su, F., Xu, L. and Yan, Y. (2018). Identification of a hot-spot to enhance: Candida rugosa lipase thermostability by rational design methods. RSC Advances, 8(4), 1948-1957. https://doi.org/10.1039/c7ra11679a

Liu, S.-D., Cao, S.-G., DING, Z.-T., Sun, L.-F., Zhang, N.-X., Liang, Q.-Z., Liu, H.-H. and Yang, H. (1995). A New Method for Estimating the Selectivity of Lipases for Fatty Acids and Fatty Alcohols in Organic Solvents. Annals of the New York Academy of Sciences, 750(1), 209-214. https:// doi.org/10.1111/j.1749-6632.1995.tb19953.x

Liu, Y., Chen, D. and Yan, Y. (2013). Effect of ionic liquids, organic solvents and supercritical $\mathrm{CO} 2$ pretreatment on the conformation and catalytic properties of Candida rugosa lipase. Journal of Molecular Catalysis B Enzymatic, 90, 123-127. https://doi.org/10.1016/j.molcatb.2013.01.028

Lotti, M. and Alberghina, L. (2007). Lipases: Molecular structure and function. In Polaina, J. and MacCabe, A. (Eds.), Industrial Enzymes: Structure, Function and Applications., p. 263-281. Dordrecht, Switzerland: Springer. https://doi.org/10.1007/14020-5377-0 16

Lotti, M., Tramontano, A., Longhi, S., Fusetti, F., Brocca, S., Pizzi, E. and Alberghina, L. (1994). Variability within the Candida rugosa upases family. Protein Engineering, Design and Selection, 7(4), 531 -535. https://doi.org/10.1093/protein/7.4.531

Malcata, F.X., Reyes, H.R., Garcia, H.S., Hill, Jr, C.G. Amundson, C.H. (1992). Kinetics and mechanisms of reactions catalyzed by immobilized lipases. Enzyme Microbial Technology, 14(6), 426-446. https://doi.org/10.1016/0141-0229(92)90135-B

Mancheño, J.M., Pernas, M.A., Martínez, M.J., Ochoa, B., Rúa, M.L. and Hermoso, J.A. (2003). Structural insights into the lipase/esterase behavior in the Candida rugosa lipases family: Crystal structure of the lipase 2 isoenzyme at $1.97 \AA$ resolution. Journal of Molecular Biology, 332(5), 1059-1069. https:// doi.org/10.1016/j.jmb.2003.08.005

McMahon, C., Baier, A.S., Pascolutti, R., Wegrecki, M., Zheng, S., Ong, J.X., Erlandson, S.C., Hilger, D., Rasmussen, S.G.F., Ring, A.M., Manglik, A. and 
Kruse, A.C. (2018). Yeast surface display platform for rapid discovery of conformationally selective nanobodies. Nature Structural and Molecular Biology, 25, 289-296. https://doi.org/10.1038/ s41594-018-0028-6

Monier, M., El-sokkary, A.M.A. and Sarhan, A.A. (2010). Reactive and Functional Polymers Immobilization of Candida rugosa lipase on modified natural wool fibers. Reactive and Functional Polymers, 70(2), 122-128. https:// doi.org/10.1016/j.reactfunctpolym.2009.11.004

Nitbani, F.O., Juminaa, Siswanta, D. and Solikhah, E.N. (2015). Reaction path synthesis of monoacylglycerol from fat and oils. International Journal of Pharmaceutical Sciences and Research, 35, 126136. https://doi.org/10.1007/s11746-003-0823-9

Noureddini, H., Gao, X. and Joshi, S. (2003). Immobilization of Candida rugosa Lipase by SolGel Entrapment. Journal of the American Oil Chemical Society, 80(11), 1077-1083.

Osborn, H.T. and Akoh, C.C. (2002). Structured Lipids Novel Fats with Medical, Nutraceutical, and Food Applications. Comprehensive Reviews in Food Science and Food Safety, 1(3), 93-103. https:// doi.org/10.1111/j.1541-4337.2002.tb00010.x

Patel, V., Gajera, H., Gupta, A., Manocha, L. and Madamwar, D. (2015). Synthesis of ethyl caprylate in organic media using Candida rugosa lipase immobilized on exfoliated graphene oxide: Process parameters and reusability studies. Biochemical Engineering Journal, 95, 62-70. https:// doi.org/10.1016/j.bej.2014.12.007

Pleiss, J., Fischer, M. and Schmid, R.D. (1998). Anatomy of lipase binding sites: The scissile fatty acid binding site. Chemistry and Physics of Lipids, 93(1-2), 67-80. https://doi.org/10.1016/S0009-3084 (98)00030-9

Rajendran, A., Palanisamy, A. and Thangavelu, V. (2009). Lipase Catalyzed Ester Synthesis for Food Processing Industries. Brazilian Archives of Biology and Technology, 52, 207-219. https:// doi.org/10.1590/S1516-89132009000100026

Rezaei, K., Jenab, E. and Temelli, F. (2007). Effects of water on enzyme performance with an emphasis on the reactions in supercritical fluids. Critical Reviews in Biotechnology, 27(4), 183-195. https:// doi.org/10.1080/07388550701775901

Rosa, B.H., Silva, G.S., Conceição, G.J.A., Carvalho, R.A., Aguiar-Oliveira, E., Maldonado, R.R. and Kamimura, E.S. (2017). Application of partially concentrated Candida rugosa lipase in the enzymatic synthesis of geranyl acetate in organic solvent.
Biocatalysis and Agricultural Biotechnology, 12, 9095. https://doi.org/10.1016/j.bcab.2017.09.005

Rúa, M.L. and Ballesteros, A. (1994). Rapid purification of two lipase isoenzymes from Candida rugosa. Biotechnology Technics 8, 21-26. https:// doi.org/10.1007/BF00207628

Sabuquillo, P., Reina, J., Fernandez-Lorente, G., Guisan, J.M. and Fernandez-Lafuente, R. (1998). "Interfacial affinity chromatography" of lipases: Separation of different fractions by selective adsorption on supports activated with hydrophobic groups. Biochim. Biophys. Acta - Protein Structure. Molecular Enzymology, 1388(2), 337-348. https:// doi.org/10.1016/S0167-4838(98)00183-6

Sharma, R.K., O’Neill, C.A., Ramos, H.A.R., Thapa, B., Barcelo-Bovea, V.C., Gaur, K. and Griebenow, K. (2019). Candida rugosa lipase nanoparticles as robust catalyst for biodiesel production in organic solvents. Biofuel Research Journal, 6(3), 10251038. https://doi.org/10.18331/BRJ2019.6.3.3

Singh, A.K. and Mausumi, M. (2016). Enzymatic Synthesis of Mono- and Diglyceride Using Lipase From Candida rugosa Immobilized Onto Cellulose Acetate-Coated $\mathrm{Fe}_{2} \mathrm{O}_{3}$ Nanoparticles. Arabian Journal of Sciences and Engineering, 41, 25532561. https://doi.org/10.1007/s13369-016-2036-3

Srivastava, A., Aoh, C.C., Chang, S.-W., Lee, G.-C. and Shaw, J.-F. (2006). Candida rugosa Lipase LIP1Catalyzed Transesterification To Produce Human Milk Fat Substitute. Journal of Agricultural and Food Chemistry, 54, 5175-5181. https:// doi.org/10.1021/jf060623h

Subroto, E. (2020). Monoacylglycerols and diacylglycerols for fat - based food products: a review. Food Research, 4, 932-943. https:// doi.org/10.26656/fr.2017.4(4).398

Subroto, E., Supriyanto, Utami, T. and Hidayat, C. (2019). Enzymatic glycerolysis-interesterification of palm stearin-olein blend for synthesis structured lipid containing high mono- and diacylglycerol. Food Science and Biotechnology, 28, 511-517. https://doi.org/10.1007/s10068-018-0462-6

Subroto, E., Tensiska, T., Indiarto, R., Marta, H. and Wulan, A.S. (2018). Physicochemical and sensorial properties of recombined butter produced from milk fat and fish oil blend. Bioscience Research, 15, 3733 -3740 .

Subroto, E., Wisamputri, M.F., Supriyanto, Utami, T. and Hidayat, C. (2020). Enzymatic and chemical synthesis of high mono- and diacylglycerol from palm stearin and olein blend at different type of reactor stirrers. Journal of the Saudi Society of 
Agricultural Sciences, 19(1), 31-36. https:// doi.org/10.1016/j.jssas.2018.05.003

Tarnowska, K., Kostecka, M., Piotrkowicz, A., Łobacz, M. and Kowaiski, B. (2013). Interesterification of goose fat and rapeseed oil mixture using Candida rugosa lipase immobilized in alginate beads. Rivista Italiana delle Sostanze Grasse, 90(2), 95-105.

Turner, N.A., Needs, E.C., Khan, J.A. and Vulfson, E.N. (2001). Analysis of conformational states of Candida rugosa lipase in solution: Implications for mechanism of interfacial activation and separation of open and closed forms. Biotechnology and Bioengineering, 72(1), 108-118. https:// doi.org/10.1002/1097-0290(20010105)72:1<108::aid -bit14>3.3.co;2-z

Vanleeuw, E., Winderickx, S., Thevissen, K., Lagrain, B., Dusselier, M., Cammue, B.P.A. and Sels, B.F. (2019). Substrate-Specificity of Candida rugosa Lipase and Its Industrial Application. ACS Sustainable Chemistry and Engineering, 7, 1582815844.

https://doi.org/10.1021/ acssuschemeng.9b03257

Wang, S., Zheng, D., Yin, L. and Wang, F. (2017). Preparation, activity and structure of cross-linked enzyme aggregates (CLEAs) with nanoparticle. Enzyme Microbial Technology, 107, 22-31. https:// doi.org/10.1016/j.enzmictec.2017.07.008

Widmann, M., Juhl, P.B. and Pleiss, J. (2010). Structural classification by the Lipase Engineering Database: A case study of Candida antarctica lipase A. BMC Genomics, 11, 1-8. https://doi.org/10.1186/14712164-11-123

Willis, W.M. and Marangoni, A.G. (2002). Enzymatic Interesterification. In Akoh, C.C. and Min, D.B. (Eds.), Food Lipids Chemistry, Nutrition and Biotechnology. New York: Marcel Dekker, Inc,

Wu, J.C., Ding, H., Song, B.D., Hayashi, Y., Talukder, M.M.R. and Wang, S.C. (2003). Hydrolytic reactions catalyzed by surfactant-coated Candida rugosa lipase in an organic-aqueous two-phase system. Process Biochemistry, 39(2), 233-238. https:// doi.org/10.1016/S0032-9592(03)00070-0

Wu, W.H., Akoh, C.C. and Phillips, R.S. (1996). Lipasecatalyzed stereoselective esterification of DLmenthol in organic solvents using acid anhydrides as acylating agents. Enzyme Microbial Technology, 18 (7), 536-539. https://doi.org/10.1016/0141-0229(95) 00182-4

Yesiloglu, Y. and Kilic, I. (2004). Lipase-Catalyzed Esterification of Glycerol and Oleic Acid. Journal of the American Oil Chemist Society, 81(3), 281-284. https://doi.org/10.1007/s11746-004-0896-5
Yigitoglu, M. and Temoçin, Z. (2010). Immobilization of Candida rugosa lipase on glutaraldehyde-activated polyester fiber and its application for hydrolysis of some vegetable oils. Journal of Molecular Catalysis $B \quad$ Enzymatic, 66(1-2), 130-135. https:// doi.org/10.1016/j.molcatb.2010.04.007

Yilmaz, E., Can, K., Sezgin, M. and Yilmaz, M. (2011). Immobilization of Candida rugosa lipase on glass beads for enantioselective hydrolysis of racemic Naproxen methyl ester. Bioresource Technology, 102(2), 499-506. https://doi.org/10.1016/ j.biortech.2010.08.083

Zhao, K., Chen, B., Li, C., Li, X., Li, K. and Shen, Y. (2018). Research Article Immobilization of Candida rugosa lipase on glutaraldehyde-activated Fe3O4@chitosan as a magnetically separable catalyst for hydrolysis of castor oil. European Journal of Lipid Science and Technology, 120(1), 110. https://doi.org/10.1002/ejlt.201700373 